\title{
Effect of carbon and oxygen fugacity on the storage of water in the transition zone
}

\author{
NATHALIE BOLFAN-CASANOVA ${ }^{1}$ AND MARTINEK \\ LOÏS $^{2}$ \\ ${ }^{1} \mathrm{CNRS}$ \\ ${ }^{2}$ Laboratoire Magmas et Volcans
}

Presenting Author: nathalie.bolfan@uca.fr

The Earth's transition zone is potentially a zone within the mantle with a high water storage capacity due to its constitutive minerals, wadsleyite and ringwoodite. This study aims to experimentally constrain the water storage capacities of olivine and wadsleyite at a depth around $410 \mathrm{~km}$ (13.5 GPa) under water-saturated conditions, as a function of temperature, oxygen fugacity and carbon content. Experiments have been conducted in the multi-anvil press, with sealed double capsules to preserve fluids. The water contents of minerals were measured by Raman spectroscopy following the new method of Martinek and BolfanCasanova (2021).

We will show the effect of carbon and oxygen fugacity on the solidus temperature as well as on the water storage capacity. This study points out that even under reducing conditions and in the presence of carbon, the water content at the bottom of the upper mantles remains significant.

\section{Reference:}

Martinek L. and Bolfan-Casanova N., Water quantification in olivine and wadsleyite by Raman spectroscopy, 2020,in press in American Mineralogist, DOI: https://doi.org/10.2138/am-20207264. 